\title{
A Wind Power and Load Prediction Based Frequency Control Approach for Wind-Diesel-Battery Hybrid Power System
}

\author{
Chao Peng, ${ }^{1}$ Zhenzhen Zhang, ${ }^{2}$ and Jia $\mathrm{Wu}^{1}$ \\ ${ }^{1}$ School of Automation Engineering, University of Electronic Science and Technology of China, Chengdu 611731, China \\ ${ }^{2}$ College of Electrical \& Information Engineering, Southwest University for Nationalities, Chengdu, Sichuan 610041, China \\ Correspondence should be addressed to Zhenzhen Zhang; zhangzhenzhen.isit@gmail.com
}

Received 16 August 2015; Revised 24 October 2015; Accepted 4 November 2015

Academic Editor: Dongsuk Kum

Copyright (c) 2015 Chao Peng et al. This is an open access article distributed under the Creative Commons Attribution License, which permits unrestricted use, distribution, and reproduction in any medium, provided the original work is properly cited.

\begin{abstract}
A frequency control approach based on wind power and load power prediction information is proposed for wind-diesel-battery hybrid power system (WDBHPS). To maintain the frequency stability by wind power and diesel generation as much as possible, a fuzzy control theory based wind and diesel power control module is designed according to wind power and load prediction information. To compensate frequency fluctuation in real time and enhance system disturbance rejection ability, a battery energy storage system real-time control module is designed based on ADRC (active disturbance rejection control). The simulation experiment results demonstrate that the proposed approach has a better disturbance rejection ability and frequency control performance compared with the traditional droop control approach.
\end{abstract}

\section{Introduction}

Remote Area Power Supply (RAPS) systems which are used to supply power for rural and remote areas, including island, could not rely on the main grid supply system. The power supply of such areas is always provided with diesel power generation, due to its merits of low installation cost, high reliability, and simple operation. The major drawbacks of this type of power generation is finite fuel, low utilization efficiency, high transportation cost, environmental pollution, and so on [1].

Recently, more and more RAPS systems use renewable power generation, such as wind power, to overcome the draws of diesel power generation. However, the active power output of wind power generation is random and fluctuant, which will seriously affect the stability of RAPS [2]. To solve this problem, wind-diesel-battery hybrid power system (WDBHPS) is introduced, which have become a popular power generation system used in RAPS. It could utilize wind power generation to reduce the use of diesel generators and environmental pollution and utilize battery energy storage system (BESS) to compensate the wind power fluctuation.

Frequency stability reflects the active power balance between the supply and demand, which is important factor in operation security and stability of the wind-diesel-battery hybrid power system. The fluctuation of wind and load would cause system frequency deviation and fluctuation. Thus, frequency control problem is main problem which hinder the development and utilization of wind-diesel-storage hybrid system in practice.

Currently, more and more scholars focus on the research on the frequency control of wind-diesel hybrid power system. Droop control based frequency control approach is the mostly used in wind-diesel hybrid power system in practice [3]. The traditional droop control use a fixed droop coefficient to increase or decrease the active power output of power sources when load demand changes. It could not avoid large deviation of frequency or voltage amplitude for its fixed droop coefficient. Therefore, many scholars studied the enhanced droop control approach. To reduce magnitude of frequency change, an adaptive droop control approach which could adjust the droop coefficient according to the change of active power and load was proposed in [4]. To eliminate the static error of frequency, an integral controller is introduced into frequency droop control in [5]. But its parameter selection is troublesome. In [6], a centralized frequency control strategy is presented, which calculates allocated active power of wind power turbine, diesel generator, and discharging/charging 


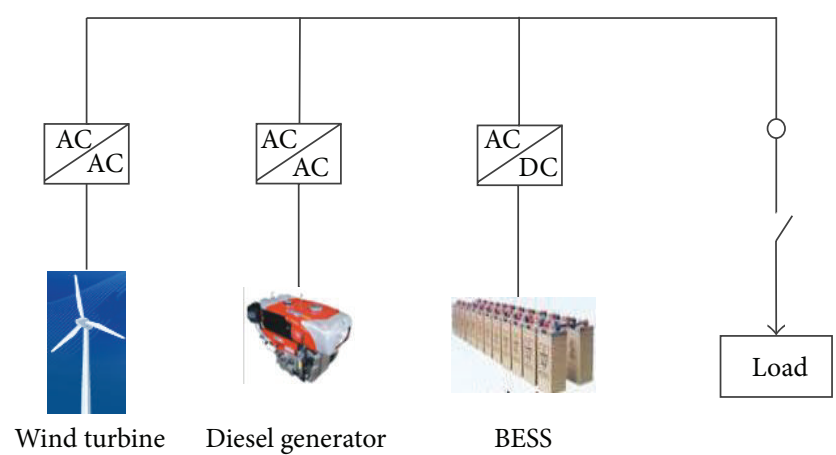

FIGURE 1: Wind-diesel-battery hybrid power system.

power of BESS according to the deviation of frequency. In [7], a proportional-integral (PI) control based frequency control approach was presented to maintain the balance between power generation and load demand. In [8], a fuzzy logic based supervisory frequency control approach was proposed to maintain the frequency stability of wind-diesel hybrid power system.

Most above frequency control approaches only use BESS to compensate the frequency deviation caused by wind power and load fluctuation and maintain power-load balance by diesel generator. Very few of them consider regulating the active power output of wind turbine to reduce frequency fluctuation. Meanwhile, they did not utilize prediction information of wind power and load to stabilize WDBHPS's frequency. The developments of wind power prediction technology and load prediction technology for microgrid, such as wavelet transformed based wind power prediction approach [9], grey model based wind power prediction model [10], artificial neural network based load prediction approach [11], and bilevel prediction strategy based load prediction approach [12], make their application become possible. If the prediction information could be taken into account in frequency control, the active power output of wind turbine and diesel generator could be regulated to reduce the frequency deviation caused by wind power and load fluctuation.

In this paper, a wind power and load prediction based frequency control approach is proposed for WDBHPS. In this approach, a fuzzy control based wind and diesel power control module is used to reduce frequency deviation by wind turbine and diesel generator according to the wind power and load prediction information. To overcome the draws of traditional droop control, such as difficulty of droop coefficient adjusting, static error of frequency control, and poor disturbance rejection ability, an ADRC based real-time control module of BESS is used to compensate the real-time frequency fluctuation.

\section{Wind Power and Load Prediction Based Frequency Control Approach}

Wind-diesel-battery hybrid power system is shown in Figure 1. As seen in Figure 1, this system consists of a wind turbine, diesel generator, BESS, AC/AC transformers, and

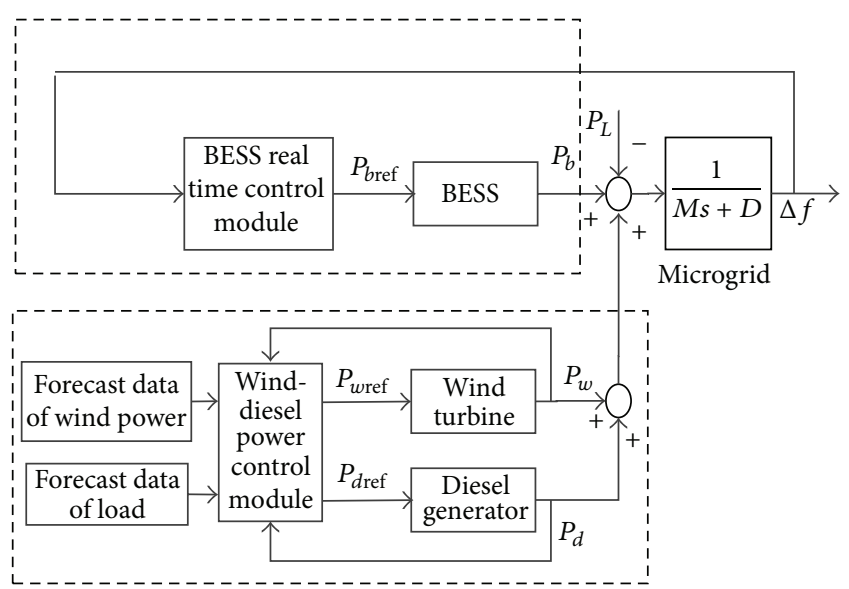

FIGURE 2: Control structure of wind power and load prediction based frequency control.

DC/AC convert. The output power of wind turbine and diesel generator and charging/discharging power of BESS are controlled to keep power-load balance and frequency stable in the system.

The control scheme of the proposed control approach is shown in Figure 2, where $P_{w \mathrm{ref}}$ and $P_{w}$ are the reference of active power output and actual active power output of wind turbine, respectively, $P_{d \text { ref }}$ and $P_{d}$ are the reference of active power output and actual active power output of diesel generator, respectively, and $P_{b \text { ref }}$ and $P_{b}$ are the reference of charging/discharging power and actual charging/discharging power of BESS, respectively. $P_{L}$ is the actual load of system, and $\Delta f$ is the system frequency deviation.

As seen in Figure 2, the proposed frequency control system mainly consists of two modules: wind-diesel power control module and BESS real-time control module. The winddiesel power control module regulates the active power output of wind turbine and diesel generator according to wind power and load prediction information. It could regulate the active power output of wind turbine and diesel generator to track the predicted load as close as possible, so as to reduce the frequency deviation to be as small as possible. The winddiesel power control module is designed based on fuzzy control, which could choose different rules based on wind power and load prediction information. An active disturbance rejection control (ADRC) based BESS real-time control module is designed to compensate the frequency fluctuation in real time, which could use the extended state observer to estimate the disturbance and compensate the real-time frequency fluctuation caused by wind power and load fluctuation.

\section{Wind-Diesel Power Control Module}

The scheme of wind-diesel power control module is shown in Figure 3. It consists of three parts: interpolation module, power control, and correction module.

3.1. Interpolation Module. The interpolation module determines the predictive value of wind power and load between each two adjacent prediction periods for power control, when 


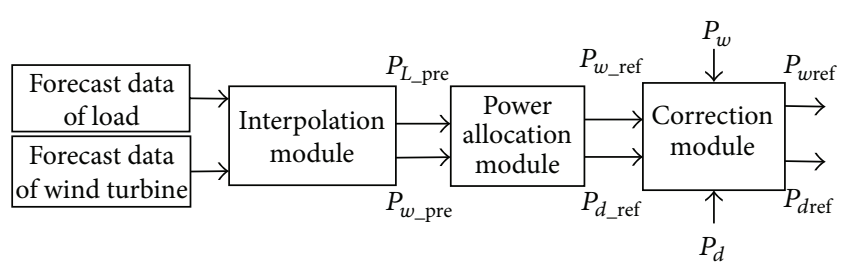

FIGURE 3: The scheme of wind-diesel control module.

prediction period is unmatched with control period. The interpolation module utilizes linear interpolation method to calculate and smooth predictive value at control period. Assumes that the prediction period is $T$ whose unit is $\mathrm{s}$ (seconds), the predictive value is $y_{0}$ at $t_{0}$, and the predictive value is $y_{1}$ at $t_{0}+T$. The linear interpolation formula is as follows:

$$
y(t)=a t+b,
$$

where $t_{0} \leq t \leq t_{0}+T$. Replace $t$ and $y$ in (1) by values of $\left(t_{0}, y_{0}\right)$ and $\left(t_{0}+T, y_{1}\right)$, and coefficients $a$ and $b$ can be obtained:

$$
\begin{aligned}
& a=\frac{y_{1}-y_{0}}{T}, \\
& b=\frac{\left(T+t_{0}\right) y_{0}-t_{0} y_{1}}{T} .
\end{aligned}
$$

3.2. Power Calculation Module. The design objective of power calculation module is to calculate reference power for wind turbine and diesel generation, which could keep the system power balance between generating power and demanding load under the premise of using wind energy as much as possible. Its control strategy is designed as follows:

(1) When $P_{L_{\text {_pre }}}<P_{w_{\text {_pre }}}$, that is, prediction value of load is less than the prediction value of wind power, the load fluctuation would be compensated by wind turbine alone and reference power of diesel generator could be zero. The control of the power value is shown as follows:

$$
\begin{aligned}
& P_{w_{\text {ref }}}=P_{L_{-\mathrm{pre}}}, \\
& P_{d_{\text {_ref }}}=0 .
\end{aligned}
$$

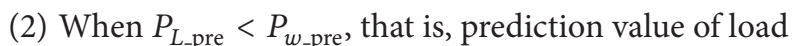
is equal to or greater than the prediction value of wind power, the reference power of wind power could be set to the prediction value of wind power to maximize the use of wind power and the frequency fluctuation would be compensated by diesel generator. The calculated reference power values for wind turbine and diesel generator are shown as follows:

$$
\begin{aligned}
& P_{w_{-} \text {ref }}=P_{w_{- \text {pre }}}, \\
& P_{d_{\text {_ref }}}=P_{L_{\text {_pre }}}-P_{w_{\text {_ref }}} .
\end{aligned}
$$

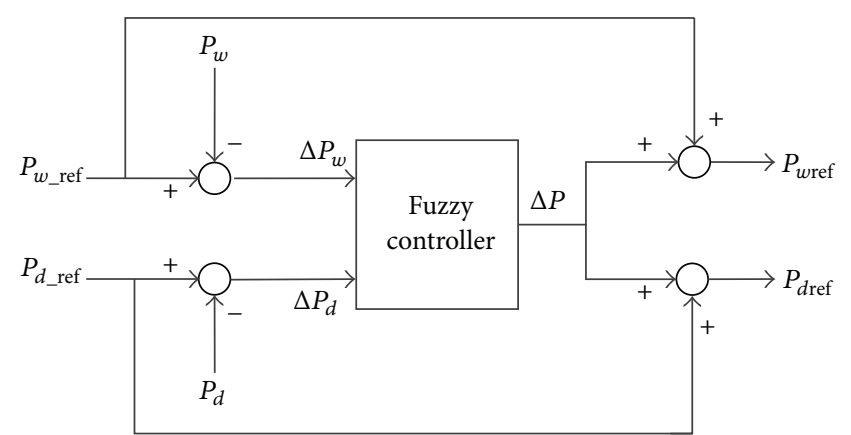

FIGURE 4: Control structure of correction module.

3.3. Correction Module. Correction module adjusts the reference power calculated by power calculation module according to the restraints of active power output change of wind turbine and diesel generator. When wind speed fluctuates sharply, the active power output of wind turbine would fluctuate sharply if wind turbine tracks the calculated reference power in (4) directly. Although diesel generator can be controlled to output any value between zero and the rated power, the rate of change of its power has its constraint.

The objective of correction module is reducing the change of active power output of wind turbine, the operation of diesel generator. The correction module is designed based on fuzzy control, which utilizes the wind power and load prediction information to adjust the active power output of wind turbine and diesel generator.

The fuzzy logic controller for correction module uses two single inputs and two-dimensional output of the structure. Its structure is shown in Figure 4.

The input variables to the fuzzy logic controller are as follows.

The first input variable is the error between reference power and actual active power output of wind turbine $\Delta P_{w}$, that is, $P_{w \text { ref }}-P_{w}$. The second input variable is the error between reference power and actual active power output of diesel generator $\Delta P_{d}$.

The output variable is adjusting power $\Delta P$ which is used to adjust the reference power of wind turbine and diesel generator calculated in power calculation module:

$$
\begin{aligned}
& P_{w \text { ref }}=P_{w \_ \text {ref }}+\Delta P, \\
& P_{d \text { ref }}=P_{d_{\text {ref }}}+\Delta P .
\end{aligned}
$$

Define language variable of $\Delta P_{w}$ as $E_{1}$, language variable of $\Delta P_{d}$ as $E_{2}$, language variable of $\Delta P$ as $U$, respectively. The fuzzy set of input variables and output variable is $\{\mathrm{NB}, \mathrm{NM}$, NS, ZO, PS, PM, PB\}, which means that the change of power is \{negative big, negative middle, negative small, zero, positive small, positive middle, positive big\}.

The membership function of the two inputs and output of the fuzzy logic controller adopts the triangle membership function and are shown in Figures 5, 6, and 7. Table 1 shows the fuzzy control rule. The weighted average method is used for defuzzification. 
TABLE 1: The rule of fuzzy controller.

\begin{tabular}{|c|c|c|c|c|c|c|c|c|}
\hline \multirow[t]{2}{*}{$U$} & \multirow[t]{2}{*}{$\bar{J}$} & \multicolumn{7}{|c|}{$E_{1}$} \\
\hline & & NB & NM & NS & $\mathrm{ZO}$ & PS & PM & $\mathrm{PB}$ \\
\hline \multirow{7}{*}{$E_{2}$} & NB & $\mathrm{ZO}$ & PS & PS & PM & PM & $\mathrm{PB}$ & PB \\
\hline & $\mathrm{NM}$ & $\mathrm{ZO}$ & $\mathrm{ZO}$ & PS & PS & PM & PM & PB \\
\hline & NS & NS & $\mathrm{ZO}$ & $\mathrm{ZO}$ & PS & PS & PM & PM \\
\hline & $\mathrm{ZO}$ & NS & NS & $\mathrm{ZO}$ & $\mathrm{ZO}$ & $\mathrm{ZO}$ & PS & PS \\
\hline & PS & NM & NM & NS & NS & $\mathrm{ZO}$ & $\mathrm{ZO}$ & PS \\
\hline & PM & NB & NM & $\mathrm{NM}$ & NS & NS & $\mathrm{ZO}$ & $\mathrm{ZO}$ \\
\hline & $\mathrm{PB}$ & NB & NB & NM & NM & NS & NS & $\mathrm{ZO}$ \\
\hline
\end{tabular}

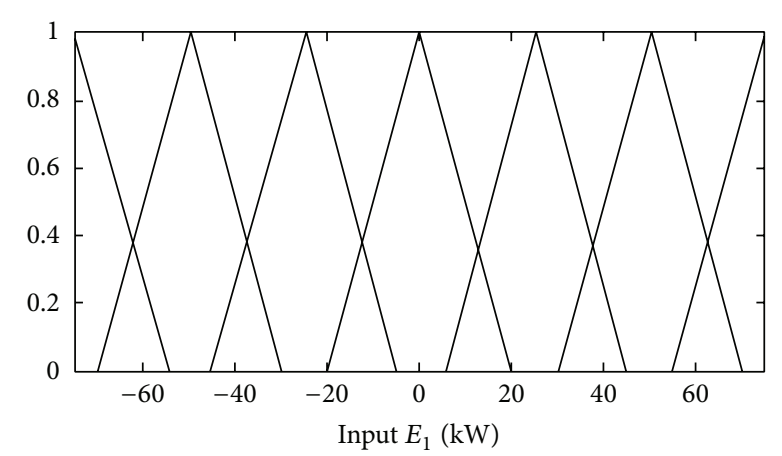

Figure 5: Membership function of the input $E_{1}$.

\section{Real-Time BESS Frequency Control Module}

The design objective of the real-time BESS frequency module is to compensate the frequency fluctuations caused by realtime wind power and load fluctuation and maintain the system frequency in rated frequency range to meet the active power-load balance.

Figure 8 shows the control structure of the real-time BESS frequency control module based on ADRC controller, where $\Delta f_{\text {ref }}$ is reference frequency error, which is always given as zero, that is, the real-time frequency error between rated frequency and actual frequency, $\Delta P_{f}$ is adjusting charging or discharging power of BESS, and $\Delta f$ is the actual frequency deviation of system. $P_{L}-P_{w}-P_{d}$ is the actual power deviation between load and power generated by wind turbine and diesel. It could be seen as disturbance to system frequency.

In Figure 8, BESS could be seen as a first-order lag loop [13]. Therefore, the whole controlled object can be seen as a concatenation of two first-order loops. A secondorder ADRC controller is used for real-time frequency BEES control.

Figure 9 shows the control structure of the second-order ADRC controller, where $G_{1}$ is the TD (Tracking Difference), $G_{2}$ is the ESO (extended state observer), $G_{3}$ is NLSEF (Nonlinear State Error Feedback), and $G_{0}$ is the controlled object.

(a) Tracking Difference $G_{1}$. The math model of TD is designed as follows:

$$
\begin{aligned}
& \dot{v}_{1}=v_{2}, \\
& \dot{v_{2}}=\mathrm{fst}\left(v_{1}, v_{2}, r, h\right),
\end{aligned}
$$

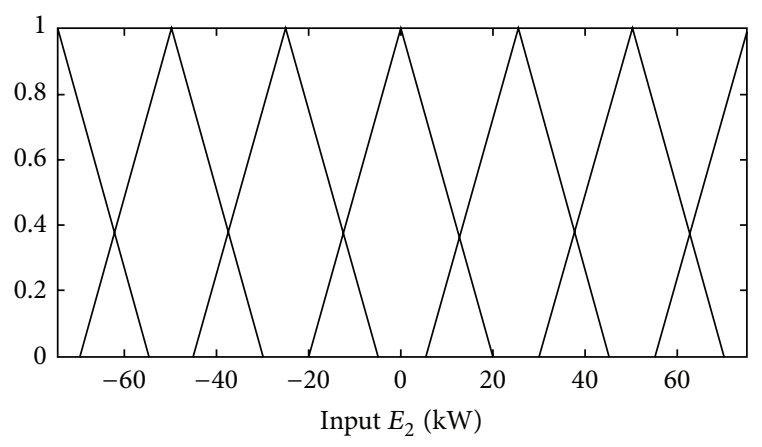

FIGURE 6: Membership function of the input $E_{2}$.

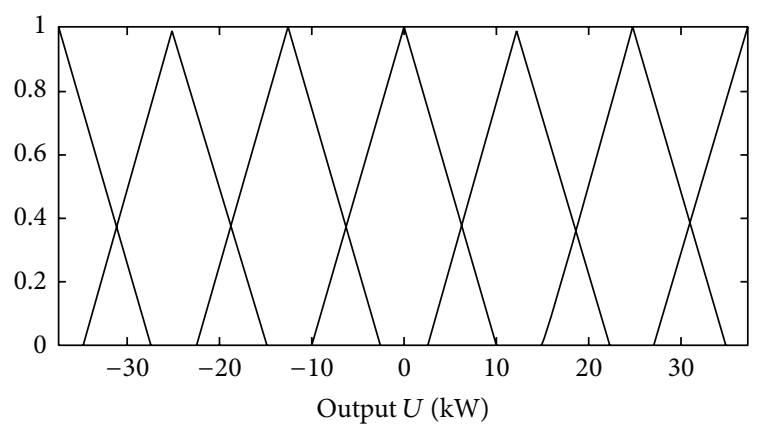

Figure 7: Membership function of the output $U$.

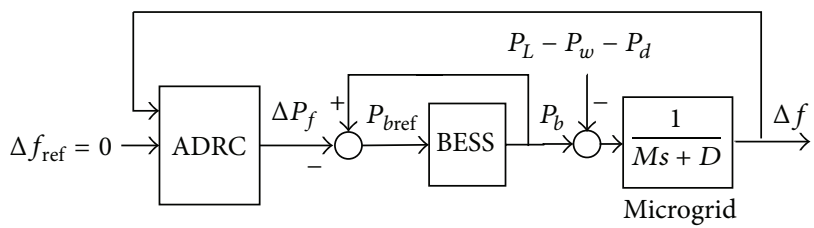

FIGURE 8: Control structure of BESS based on ADRC.

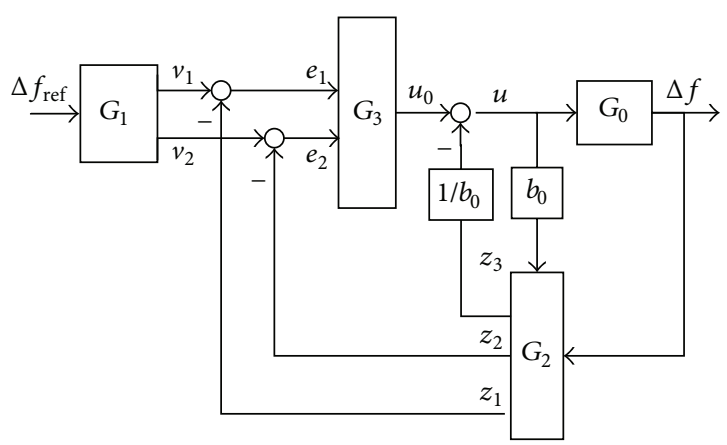

FIgURE 9: Control structure of second-order ADRC.

where function $\operatorname{fst}\left(v_{1}, v_{2}, r, h\right)$ is determined by following equation:

$$
\begin{aligned}
\delta & =r \cdot h, \\
\delta_{0} & =\delta \cdot h, \\
y & =v_{1}-\Delta f_{\text {ref }}+h \cdot v_{2},
\end{aligned}
$$




$$
\begin{aligned}
a_{0} & =\sqrt{\delta^{2}+8 r|y|}, \\
a & = \begin{cases}x_{2}+\frac{y}{h} & |y| \leq \delta_{0} \\
x_{2}+\frac{\left(a_{0}-\delta\right)}{2} \operatorname{sign}(y) & |y|>\delta_{0},\end{cases} \\
\text { fst }\left(v_{1}, v_{2}, r, h\right) & = \begin{cases}-\frac{r \cdot a}{\delta} & |a| \leq \delta \\
-r \cdot \operatorname{sign}(a) & |a|>\delta,\end{cases}
\end{aligned}
$$

where $r$ is the speed factor, $h$ is the filter factor, sign is a sign function, and $r$ and $h$ are adjustable parameters of TD.

(b) Extended State Observer $G_{2}$. The math model of ESO is designed as follows:

$$
\begin{aligned}
\varepsilon & =z_{1}-y, \\
\dot{z}_{1} & =z_{2}-\beta_{01} \cdot \varepsilon, \\
\dot{z}_{2} & =z_{3}-\beta_{02} \cdot \operatorname{fal}\left(\varepsilon, \alpha_{1}, \delta_{1}\right)+b_{0} \cdot u, \\
\dot{z}_{3} & =-\beta_{03} \cdot \operatorname{fal}\left(\varepsilon, \alpha_{2}, \delta_{1}\right),
\end{aligned}
$$

where function $\mathrm{fal}(\varepsilon, \alpha, \delta)$ is given as follows:

$$
\mathrm{fal}(\varepsilon, \alpha, \delta)= \begin{cases}|\varepsilon|^{\alpha} \operatorname{sign}(\varepsilon) & |\varepsilon|>\delta \geq 0 \\ \frac{\varepsilon}{\delta^{1-\alpha}} & |\varepsilon| \leq \delta\end{cases}
$$

In (8), by choosing appropriate $\left\{\alpha_{1}, \alpha_{2}, \delta_{1}, \beta_{01}, \beta_{02}, \beta_{03}\right\}, z_{1}$, $z_{2}$ could be used to estimate the controlled variable $y$ and its differential. $z_{3}$ could be used to estimate the disturbance.

(c) Nonlinear State Error Feedback $G_{3}$. The math model of NLSEF is designed as follows:

$$
\begin{aligned}
& e_{1}=v_{1}-z_{1}, \\
& e_{2}=v_{2}-z_{2}, \\
& u_{0}=k_{1} \cdot f \mathrm{fal}\left(e_{1}, \alpha_{3}, \delta_{2}\right)+k_{2} \mathrm{fal}\left(e_{2}, \alpha_{4}, \delta_{2}\right), \\
& u=u_{0}-\frac{z_{3}}{b_{0}},
\end{aligned}
$$

where function $\mathrm{fal}()$ is showed in (9), $z_{3}$ is the extended state variable, and $k_{1}, k_{2}, \alpha_{3}, \alpha_{4}$, and $\delta_{2}$ are the adjusting parameters of NLSEF.

(d) Control Object $G_{0}$. The structure of controlled object $G_{0}$ is shown in Figure 10, whose control variable is $u=\Delta P_{f}$, output variable is $y=\Delta f$, and disturbance is $P_{L}-P_{w}-P_{d}$.

The transfer function of control object $G_{0}$ could be written as follows:

$$
G(s)=-\frac{1}{T_{b} s(M s+D)} .
$$

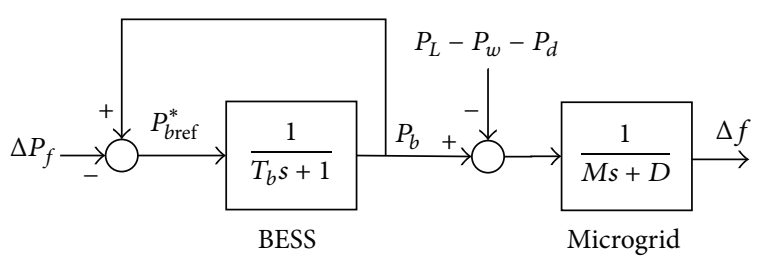

FIGURE 10: Control structure from control variable to output.

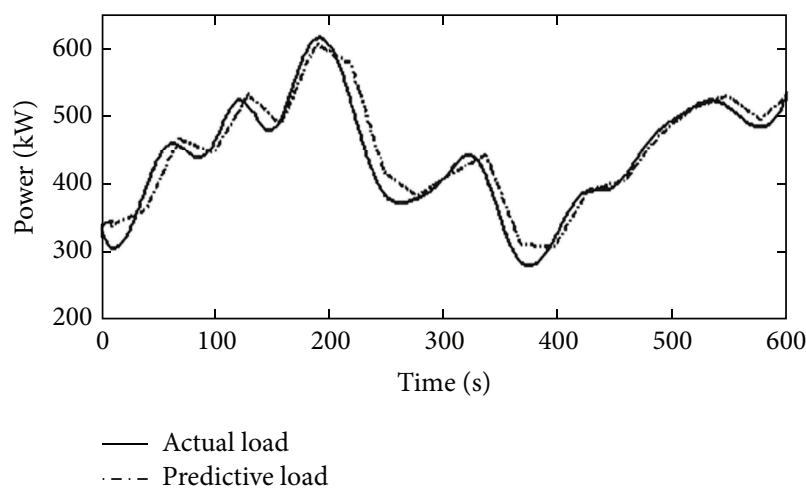

FIgure 11: Actual load and predictive load.

The corresponding state space expression of $G_{0}$ could be written as follows:

$$
\begin{aligned}
& \dot{x_{1}}=\frac{1}{M}\left(-D x_{1}+x_{2}\right), \\
& \dot{x_{2}}=-\frac{1}{T_{b}} u,
\end{aligned}
$$

where $x=\left[x_{1}, x_{2}\right]=\left[\Delta f, P_{b}\right]$ is the state variable, $y=x_{1}$ is the output, and $u=\Delta P_{f}$ is the control variable.

\section{Simulation and Analysis}

In this section, the simulation experiment of frequency control of WPBHPS will be conducted to demonstrate the effectiveness of the proposed approach. A wind-diesel-battery hybrid power system [14], which consists of a $750 \mathrm{~kW}$ wind turbine, a $350 \mathrm{~kW}$ diesel generator, and a $300 \mathrm{~kW}$ BESS with $50 \mathrm{~kW} \cdot \mathrm{h}$ capacity is used in the simulation experiments.

For comparison, two different frequency control approaches will be used in the simulation experiment: (a) the proposed control approach and (b) the control approach which control the active power output of wind turbine by maximum power point tracking (MPPT) control approach and compensate frequency deviation by diesel generator and BESS only.

A load prediction method based on artificial neural network [11] is used to predict the load. The actual load and predictive load curve is shown in Figure 11.

The actual wind speed data of wind turbines is shown in Figure 12.

A grey model based wind power prediction method [15] is used to predict the available active power of wind turbine. The predictive power of the wind turbine is shown in Figure 13. 


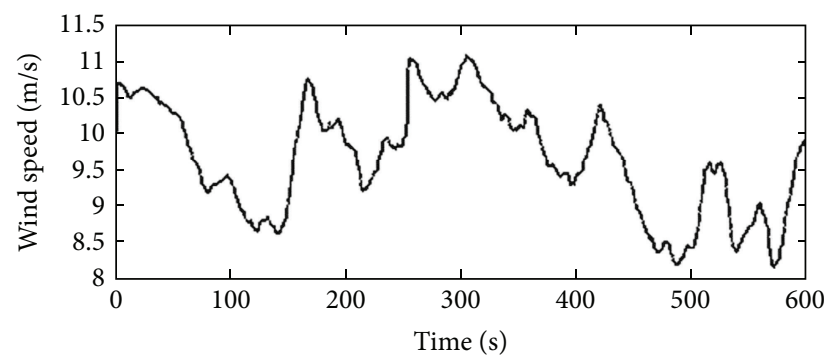

Figure 12: Actual wind speed.

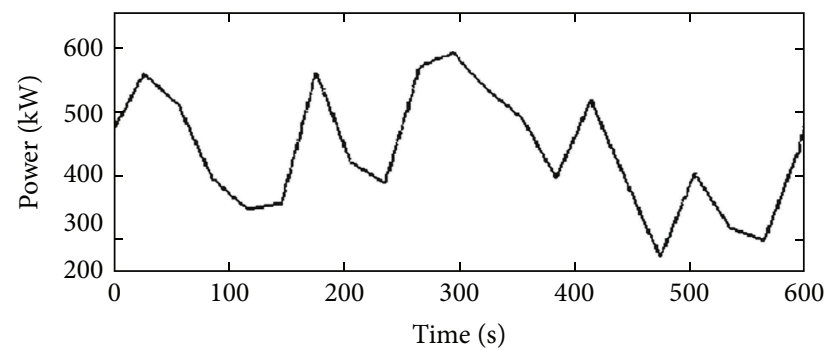

FIgURE 13: Predictive power of wind turbine.

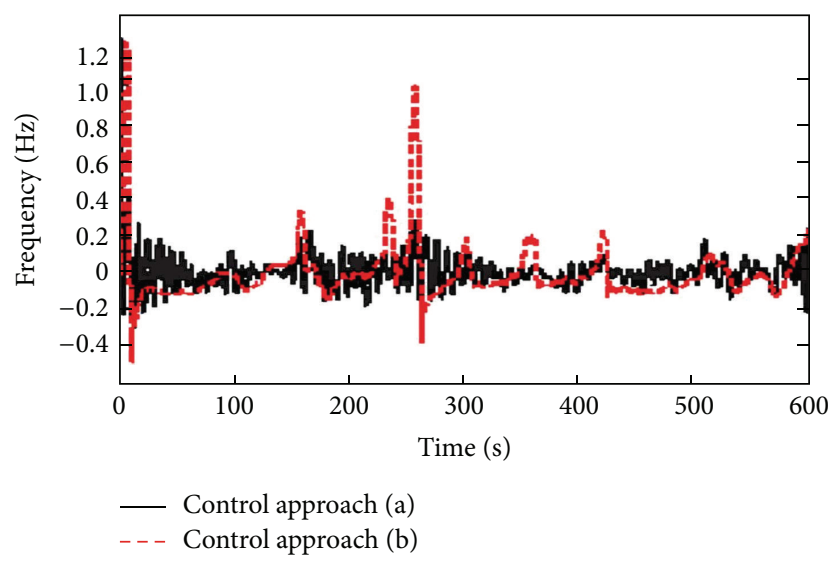

FIGURE 14: Frequency fluctuation of system.

The results of frequency control simulation experiments are shown in Figure 14. By using control approach (b), the maximum and minimum frequency deviations are $1.2411 \mathrm{~Hz}$ and $0.4772 \mathrm{~Hz}$, respectively. The maximum frequency deviation of control approach (a) is $0.4103 \mathrm{~Hz}$, which is $33.5 \%$ of that of control approach (b). The minimum frequency deviation of control approach (a) is $0.2920 \mathrm{~Hz}$, which is $61.2 \%$ of that of control approach (b). It is obvious that the frequency control performance of control approach (a) is better than approach (b).

The active power output of wind turbine and diesel generator are shown in Figures 15 and 16. As seen in them, the active power output of wind turbine and diesel generator by using control approach (a) is smoother than that by using control approach (b).

The charging/discharging power curve and SOC of BESS are shown in Figures 17 and 18. As seen in Figure 16,

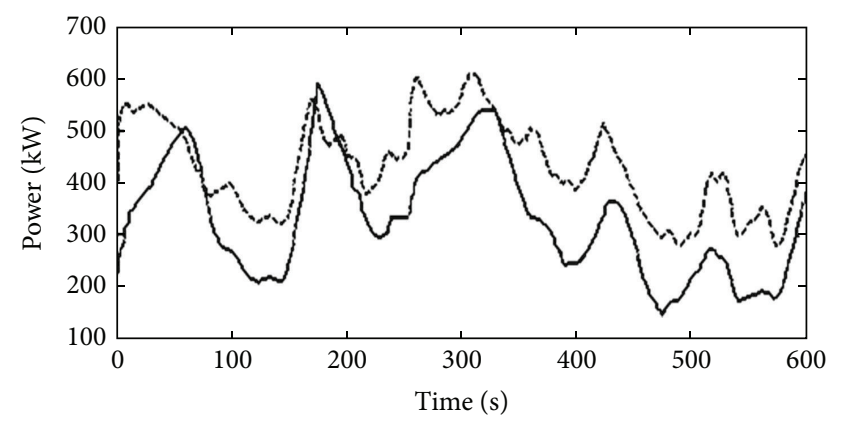

- Control approach (a)

- - - Control approach (b)

FIGURE 15: Active power output of wind turbine.

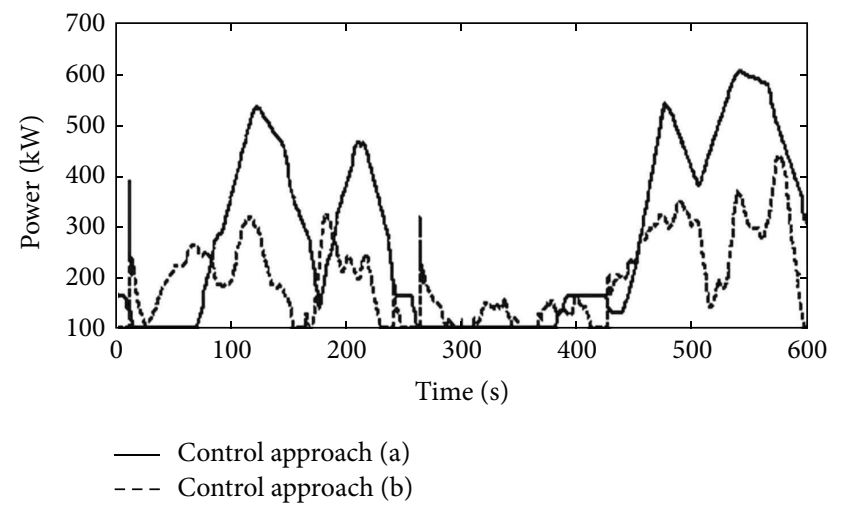

FIGURE 16: Active power output of diesel generator.

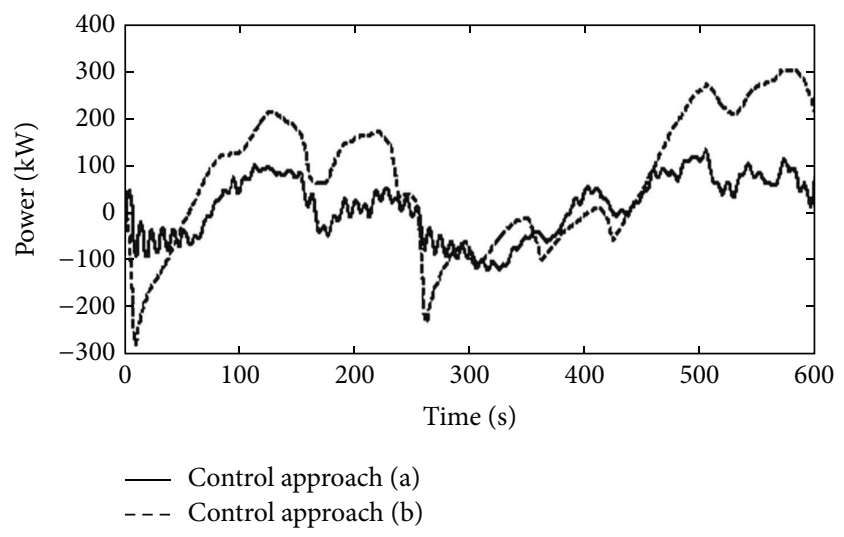

FIGURE 17: Charging/discharging power of BESS.

the charging and discharging power of BESS are much smaller by using control approach (a) compared with control approach (b). As seen in Figure 17, the initial SOC of BESS is 0.5. By using control approach (a), the SOC of BESS is around 0.5. By using control approach (b), the SOC of BESS is far below 0.5 .

\section{Conclusions}

This paper proposed a load and wind power prediction based frequency control approach for wind-diesel-battery 


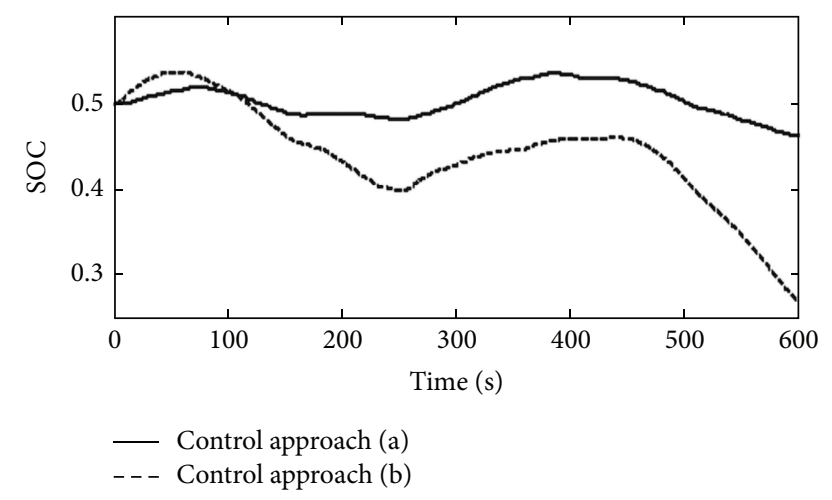

FIGURE 18: SOC of BESS.

hybrid power system. In this control approach, a winddiesel power control module is designed to regulate the active power output of wind turbine and diesel generator according to the prediction information of load and wind power, which not only reduces frequency deviation caused by fluctuation of load and wind power but also maximizes use of wind power and reduces operation of diesel generator. A real-time BESS frequency control module based on ADRC controller is used to compensate the disturbance caused by load and wind power fluctuation in real time. The simulation results demonstrate that the proposed approach has a better disturbance rejection ability and frequency control performance compared with the traditional control approach without prediction information and traditional droop control approach.

\section{Conflict of Interests}

The authors declare that there is no conflict of interests regarding the publication of this paper.

\section{Acknowledgments}

This work is being supported by the National Natural Science Foundation of China under Grant no. 61201010, Fundamental Research Funds for the Central Universities, Southwest University for Nationalities under Grant no. 2014NZYQN13, and Scientific Research Fund of Sichuan Provincial Education Department (15ZB0483).

\section{References}

[1] Z. Chen and Y. Hu, "A hybrid generation system using variable speed wind turbines and diesel units," in Proceedings of the 29th Annual Conference of the IEEE Industrial Electronics Society (IECON '03), vol. 3, pp. 2729-2734, IEEE, Roanoke, Va, USA, November 2003.

[2] M. Imanaka, Y. Onda, J. Baba, T. Yoshihara, and A. Yokoyama, "Feasibility study on compensation of power fluctuation caused by renewable energy source using desalination system in island power system," Journal of International Council on Electrical Engineering, vol. 1, no. 3, pp. 345-351, 2014.
[3] P. Basak, S. Chowdhury, S. Halder Nee Dey, and S. P. Chowdhury, "A literature review on integration of distributed energy resources in the perspective of control, protection and stability of microgrid," Renewable and Sustainable Energy Reviews, vol. 16, no. 8, pp. 5545-5556, 2012.

[4] Y. W. Zheng, M. Y. Chen, C. Li, R. Xu, and X. Xu, "A microgrid control strategy based on adaptive drooping coefficient adjustment," Automation of Electric Power Systems, vol. 37, no. 7, pp. 6-11, 2013.

[5] J. A. Peas Lopes, C. L. Moreira, and A. G. Madureira, "Defining control strategies for microgrids islanded operation," IEEE Transactions on Power Systems, vol. 21, no. 2, pp. 916-924, 2006.

[6] A. Madureira, C. Moreira, and J. P. Lopes, "Secondary loadfrequency control for micro grids in islanded operation," in Proceedings of the International Conference on Renewable Energy and Power Quality, Barcelona, Spain, 2005.

[7] T. Senjyu, T. Nakaji, K. Uezato, and T. Funabashi, "A hybrid power system using alternative energy facilities in isolated island," IEEE Transactions on Energy Conversion, vol. 20, no. 2, pp. 406-414, 2005.

[8] L. Leclercq, B. Robyns, and J.-M. Grave, "Control based on fuzzy logic of a flywheel energy storage system associated with wind and diesel generators," Mathematics and Computers in Simulation, vol. 63, no. 3-5, pp. 271-280, 2003.

[9] Y. Liu, J. Shi, Y. Yang, and W.-J. Lee, "Short-term wind power prediction based on wavelet transform-support vector machine and statistic characteristics analysis," IEEE Transactions on Industry Applications, vol. 48, no. 4, pp. 1136-1141, 2012.

[10] T. H. M. El-Fouly, E. F. El-Saadany, and M. M. A. Salama, "Improved grey predictor rolling models for wind power prediction," IET Generation, Transmission and Distribution, vol. 1, no. 6, pp. 928-937, 2007.

[11] Z. R. Li, "Short-term load forecasting based on artificial neural network," Guangxi Electric Power, vol. 25, no. 4, pp. 7-10, 2002.

[12] N. Amjady, F. Keynia, and H. Zareipour, "Short-term load forecast of microgrids by a new bilevel prediction strategy," IEEE Transactions on Smart Grid, vol. 1, no. 3, pp. 286-294, 2010.

[13] T. Senjyu, A. Uehara, and A. Yona, "Frequency control by coordination control of wind turbine generator and battery using $H_{\infty}$ control," in Proceedings of the Transmission \& Distribution Conference \& Exposition: Asia and Pacific, pp. 1-4, Seoul, The Republic of Korea, October 2009.

[14] N. Mendis, K. M. Muttaqi, S. Sayeef, and S. Perera, "A control approach for voltage and frequency regulation of a wind-dieselbattery based hybrid remote area power supply system," in Proceedings of the 36th Annual Conference of the IEEE Industrial Electronics Society (IECON '10), pp. 3054-3060, Glendale, Calif, USA, November 2010.

[15] Z. Z. Zhang, J. X. Zou, and G. Zheng, "Ultra-short term wind power prediction model based on modified grey model method for power control in wind farm," Wind Engineering, vol. 35, no. 1, pp. 55-68, 2011. 


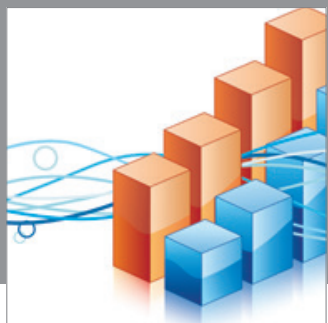

Advances in

Operations Research

mansans

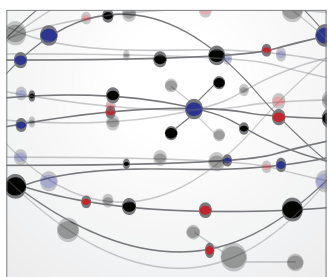

The Scientific World Journal
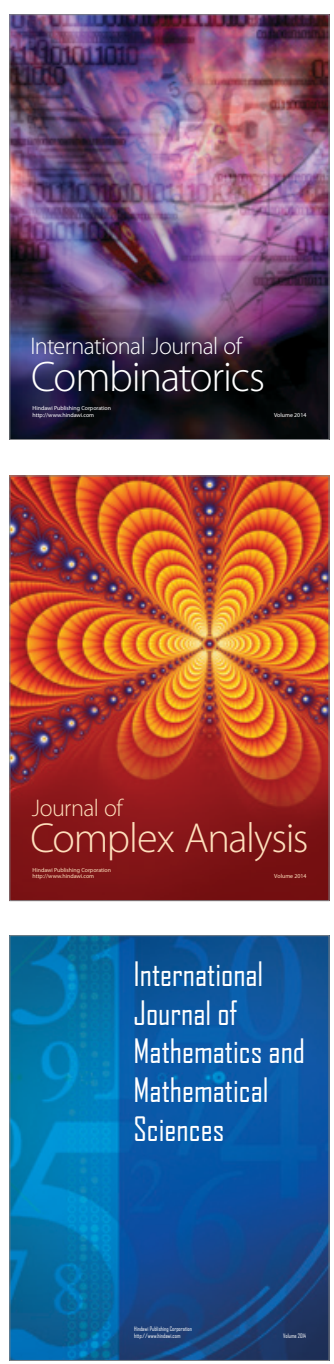
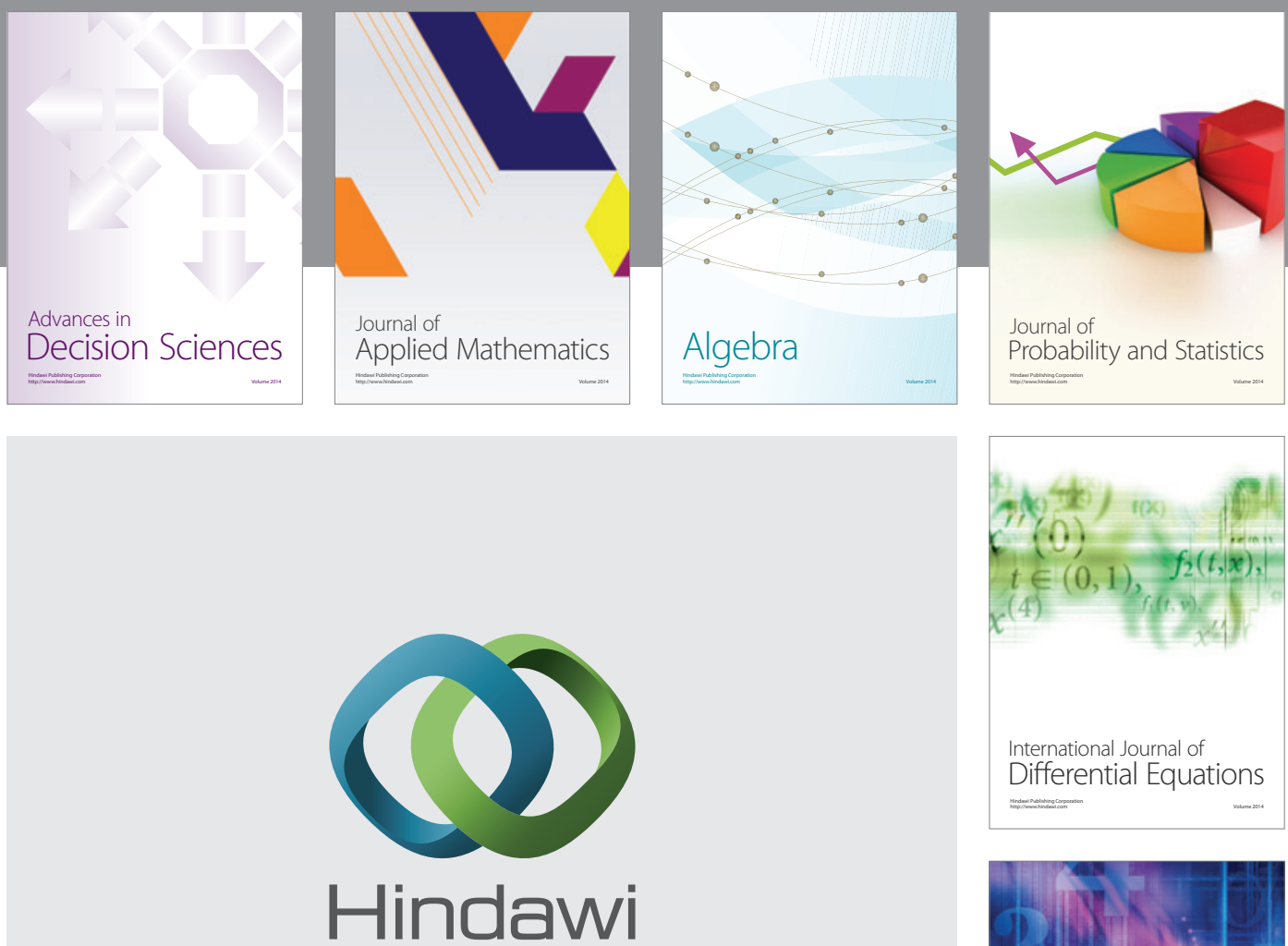

Submit your manuscripts at http://www.hindawi.com
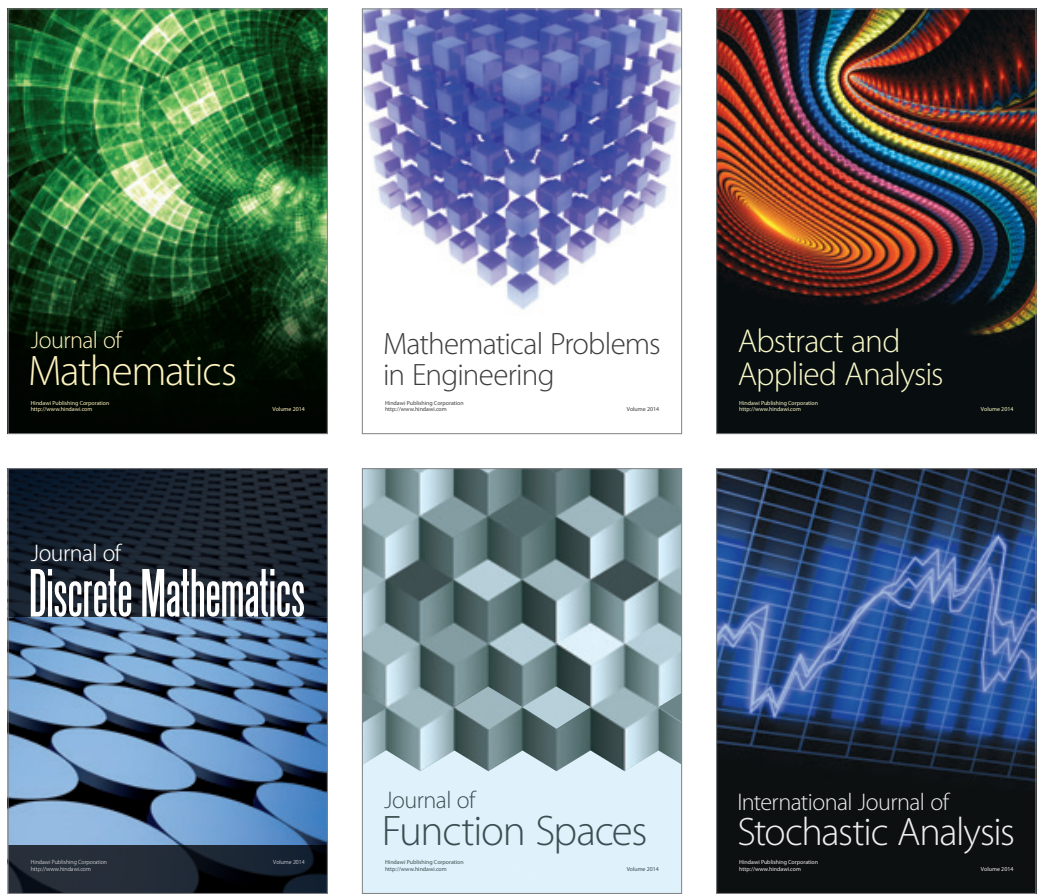

Journal of

Function Spaces

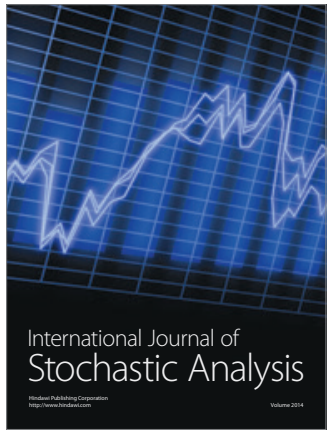

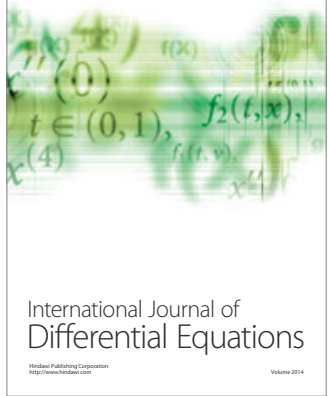
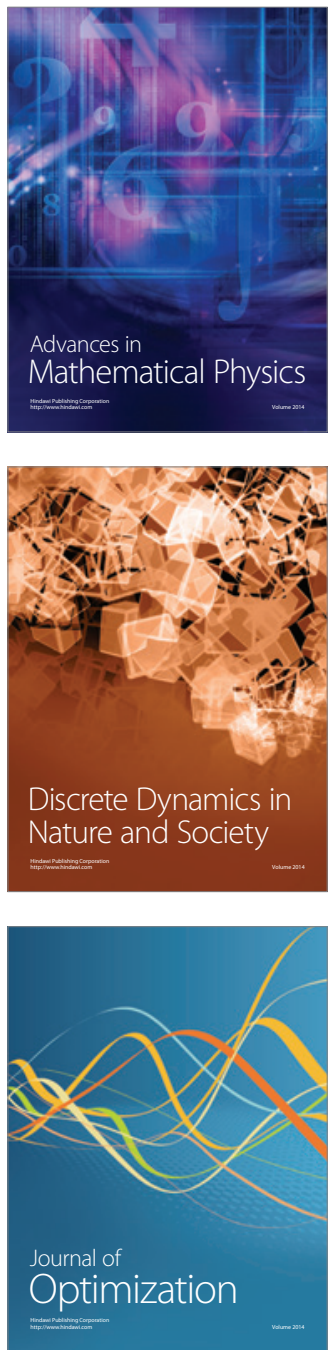